\title{
INFLUËNCIA DO TEOR DE AGREGADO E UMIDADE DA AMOSTRA NA RESISTIVIDADE ELÉTRICA DO CONCRETO OBTIDA PELO MÉTODO DIRETO
}

\author{
FARIAS, LIDIANNE DO NASCIMENTO \\ Mestranda \\ Universidade Estadual de Feira de Santana \\ Bahia; Brasil \\ eng.lidianefarias@gmail.com
}

\author{
FONTES, CINTIA MARIA ARIANI \\ Professora Doutora \\ Universidade Estadual de Feira de Santana \\ Bahia; Brasil \\ cintiafontes@gmail.com
}

\author{
LIMA, PAULO ROBERTO LOPES \\ Professor Doutor \\ Universidade Estadual de Feira de Santana \\ Bahia; Brasil \\ lima.prl.uefs@gmail.com
DIAS, ANFRANSERAI MORAIS
Professor Doutor
Universidade Estadual de Feira de Santana
Bahia; Brasil
anfranserai@ecomp.uefs.br

\section{RESUMO}

A resistividade elétrica do concreto pode ser influenciada por diversos fatores, sejam eles internos ou externos. O objetivo deste artigo foi analisar o comportamento da resistividade elétrica devido às diferenças na composição das misturas, com relação ao teor de agregado graúdo presente e atribuindo uma característica externa as mesmas, em relação ao seu teor de umidade. As misturas de concreto foram produzidas com a mesma relação água/cimento $(0,55)$ e mesmas condições de cura, no entanto, os teores de agregado graúdo utilizados alteraram-se entre o percentual de $40 \%$, $43 \%$ e $46 \%$. A resistividade elétrica do concreto foi obtida através do Método Direto, conforme procedimentos para montagem do aparato pela norma espanhola UNE 83988-1 (AENOR, 2008). Com os resultados obtidos neste estudo concluiu-se que ao aumentar o teor de agregado graúdo na produção dos concretos, há um aumento na resistividade elétrica. Palavras-chave: durabilidade, resistividade elétrica, método direto.

\section{ABSTRACT}

The electrical resistivity of concrete can be influenced by several factors, be them internal or external. The objective of this paper was to analyze the behavior of the electrical resistivity due to the differences in the composition of the mixture in relation to the content of coarse aggregate present, and to attribute an external characteristic as the same, in relation to the moisture content. As the concrete mixtures were produced under the influence of the same water/cement ratio $(0,55)$ and the same curing conditions, however, the coarse aggregate contents used are changed between $40 \%, 43 \%$ and $46 \%$. The electrical resistivity of the concrete was obtained by the Direct Method, according to the procedures for mounting the apparatus by the Spanish standard UNE 83988-1 (AENOR, 2008). With the results obtained in this article it was concluded that by increasing the coarse aggregate content in concrete production, there is a increase in electrical resistivity.

Keywords: durability, electrical resistivity, direct method.

\section{INTRODUÇÃO}

A inserção de indicadores de durabilidade durante o dimensionamento das estruturas de concreto tem estimulado o desenvolvimento de novos modelos que estimam a vida útil dos materiais (ANDRADE, 2004; SENGUL, 2014). Desta maneira, a resistividade elétrica é identificada como forma de monitoramento quanto à possível ocorrência de deterioração precoce das estruturas por meio da corrosão das armaduras possibilitando meios de preveni-la. A resistividade elétrica do concreto é caracterizada como a dificuldade com que os íons se movimentam pelo interior do concreto, além disso, fornece indicações sobre a conectividade dos poros. Por isso, pode ser utilizada como uma medida indireta da capacidade do concreto em resistir à penetração de substâncias agressivas, líquidas ou gasosas (HELENE, 1993; ANDRADE, 2004; WHITING; NAGI, 2003).

Uma das facilidades do ensaio de resistividade elétrica para verificação do processo de corrosão é a sua realização de forma não-destrutiva ao concreto, permitindo que se avalie, continuadamente, uma única peça ao longo do tempo. No entanto, é necessário considerar uma variedade de fatores que podem influenciar nos seus resultados, principalmente, 
quanto às características intrínsecas à matriz cimentícia que alteram a resistividade do concreto; os fatores ambientais que ocasionam alteração nas medidas de resistividade; e os métodos de medida utilizados (LAYSSI et al., 2015; MENDES et al., 2018; SANTOS, 2006; SENGUL, 2014; TOMLINSON et al., 2017; AZARSA; GUPTA, 2017). ). Por exemplo, fatores internos, como uma menor porosidade, resultam em uma maior resistividade e fatores externos, como umidade mais alta, reduzem os valores de resistividade.

Neste caso, a resistividade elétrica do concreto é especialmente dependente do grau de saturação dos poros da estrutura (LOPEZ; GONZALEZ, 1993). A corrente elétrica é transportada por íons que fluem através da solução de poros no concreto. Portanto, com o teor de umidade mais alto, há uma maior facilidade na mobilidade iônica, alta possibilidade de iniciação da corrosão das armaduras na estrutura e, assim, consequente redução da resistividade elétrica (SENGUL, 2014).

Como uma propriedade fortemente dependente das características de composição da mistura, a resistividade elétrica é muito sensível às alterações provenientes da pasta de cimento, devido à sua porosidade. Porém, os agregados, material que constitui entre $60 \%$ a $75 \%$ do volume total do concreto também pode influenciar os seus resultados. A interferência do agregado utilizado na composição do concreto na resistividade elétrica vem sendo estudada por alguns pesquisadores, no entanto, na literatura ainda não são encontrados muitos relatos.

Em geral, os autores indicam que a resistividade da pasta de cimento, na maiora das vezes, é muito menor que a do agregado. Isso ocorre devido a facilidade de fluxo da corrente elétrica através dos poros presentes na pasta de cimento, que em suma, é muito maior que a dos agregados. Dessa forma, ao aumentar o teor de agregado na produção dos concretos, há um possível aumento na sua resistividade elétrica, devido à obstrução da passagem de corrente elétrica causada pelas partículas de agregados praticamente não-condutoras e pela diminuição no volume da pasta cimentícia (AZARSA; GUPTA, 2017; MONFORE, 1968 apud JESUS, 2018; SENGUL, 2014).

Sengul (2014) e Hou et al. (2017) relataram que o efeito do menor volume dos agregados na resistividade ocasionam uma diminuição da resistividade elétrica do concreto, pois a condução elétrica ocorrerá essencialmente pela pasta de cimento, mais porosa. Princigallo et al. (2003) analisaram a condutividade elétrica, propriedade contrária a resistividade, e descreveram que a mesma diminui regurlamente com o aumento no teor de agregado (volume total utilizado de 0 a $75 \%$ ), e avança ao longo do tempo de hidratação. Shi (2004) apud Silva e Brito (2013) confirmaram o indicado por estes autores e justificam o comportamento como devido à ascendência da matriz cimentícia na propriedade, isto é, o maior volume de agregado implica menos pasta e, consequentemente, menos "espaço" para a mobilidade iônica.

Prosseguindo com este tipo de estudo, o objetivo deste artigo é analisar a influência do agregado graúdo na resistividade eletrica pelo método direto e alterando-se os teores de umidade. Porém, em volumes que estão dentro da faixa de utilização para composição de concretos convencionais.

\section{PROCEDIMENTO EXPERIMENTAL}

\subsection{Caracterização dos materiais}

Os materiais utilizados para a produção dos concretos foram:

Cimento Portland CPII-F32, escolhido por ser um dos compostos cimentícios mais facilmente encontrados pela região onde a pesquisa está sendo desenvolvida. Possui uma massa específica de 3,02 e conforme fabricante, uma resistência mecânica aos 28 dias de 35,7 MPa.

O agregado miúdo foi uma areia média de composição quartzosa, extraída do rio, e seca ao ar. Com massa específica de $2,61 \mathrm{~kg} / \mathrm{m}^{3}$ e um módulo de finura de 2,52. A areia empregada atendeu aos requisitos da NBR 7211 (ABNT, 2019), e está enquadrada na zona utilizável indicada pela norma, e inteiramente dentro da zona ótima. O agregado graúdo foi de composição granítica, apresentou massa específica de $2,79 \mathrm{~kg} / \mathrm{m}^{3}$ e uma dimensão máxima característica de $19 \mathrm{~mm}$. Também atendeu os limites indicados pela NBR 7211 (ABNT, 2019).

E por fim, a água utilizada para produção dos concretos foi proveniente da rede de abastecimento da Universidade Estadual de Feira de Santana - UEFS. 


\subsection{Proporção de mistura}

Para produção dos concretos foi utilizado como traço de referência 1:2,18:2,84:0,55 (BRITA_43\%) e a partir deste foram produzidas mais duas misturas alterando-se o teor de agregado graúdo. Os traços unitários mantiveram as mesmas quantidades relativas ao cimento para areia e água. Os teores de brita utilizados como percentual de volume final nas misturas foram de $40 \%, 43 \%$ e $46 \%$. A Tabela 1 mostra os traços unitários confeccionados, assim como, os consumos de cimento por $\mathrm{m}^{3}$.

Tabela 1 - Traço unitário e consumo de cimento das misturas produzidas

\begin{tabular}{c|c|c}
\hline Mistura & $\begin{array}{c}\text { Traço unitário } \\
\text { (cimento:areia:brita:água) }\end{array}$ & $\begin{array}{c}\text { Consumo de } \\
\text { cimento }\left(\mathbf{k g} / \mathbf{m}^{3}\right)\end{array}$ \\
\hline BRITA_40\% & $1: 2,18: 2,46: 0,55$ & 378 \\
\hline BRITA_43\% & $1: 2,18: 2,84: 0,55$ & 364 \\
\hline BRITA_46\% & $1: 2,18: 3,24: 0,55$ & 351 \\
\hline
\end{tabular}

As moldagens dos concretos seguiram as prescrições da NBR 5738 (ABNT, 2015) para moldagem dos corpos de prova e cura. Foram moldados corpos de prova cilíndricos ( $100 \mathrm{~mm}$ de diâmetro x $200 \mathrm{~mm}$ de altura) e adensados com vibrador de imersão. Após 24 horas, os corpos de prova foram desmoldados, identificados e colocados em cura com cal até as idades estabelecidas de ensaios.

\subsection{Métodos de ensaio}

Os concretos foram ensaiados quanto à Resistividade Elétrica conforme requisistos previstos na norma espanhola UNE 83988-1 (AENOR, 2008), quanto à Resistência à Compressão Axial conforme NBR 5739 (ABNT, 2018), quanto ao Módulo de Elasticidade conforme NBR 8522 (ABNT, 2017), quanto à Absorção de Água por Capilaridade conforme NBR 9779 (ABNT, 2012), quanto à Absorção de água por imersão conforme NBR 9778 (ABNT, 2009). Todos ensaios foram realizados aos 28 dias, exceto o ensaio de resistividade elétrica, que também foi realizado aos 56 dias.

\subsubsection{Resistividade elétrica pelo método direto}

O ensaio de resistividade elétrica foi realizado pelo Método Direto de acordo com as recomendações da norma espanhola UNE 83988-1 (AENOR, 2008). O equipamento necessário para realização das medições da resistividade por este método foi desenvolvido pelos autores. O equipamento produzido é mostrado na Figura 1.

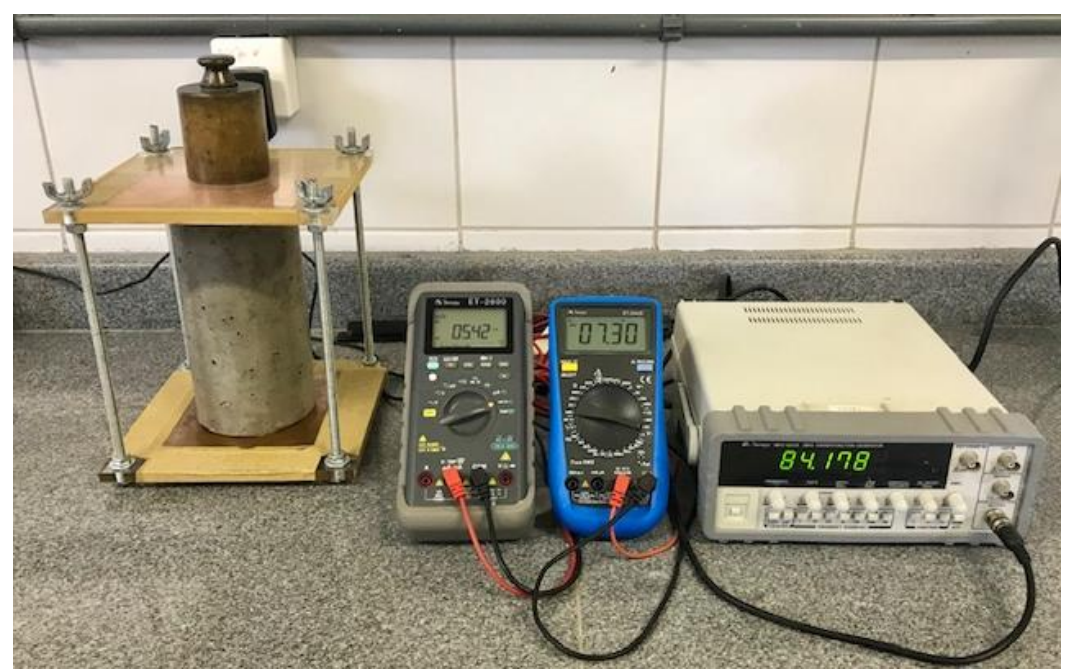

Figura 1: Equipamento utilizado para medição da resistividade pelo método direto

Para montagem do aparato foi utilizada uma fonte de corrente alternada (AC) com uma frequência estabelecida entre 82 -85 Hz. Utilizou-se também dois multímetros digitais, um para medição da corrente, outro para tensão. A tensão alternada 
obtida variou entre 7,30 - 7,40V. Os eletrodos foram compostos por duas chapas de cobre e por duas esponjas úmidas, para manter uma melhor conexão, que foram acoplados paralelamente ao corpo de prova. Ainda, para melhor contato com a superfície do concreto e passagem da corrente pelo mesmo, internamente, foi utilizado um peso de balança de 2 $\mathrm{kg}$.

As amostras foram colocadas em cura com cal. No momento da realização do ensaio se encontravam em condição saturada e foram secas cuidadosamente com um pano úmido para remoção do excesso de água antes da submissão da passagem de corrente elétrica. A resistividade elétrica das esponjas úmidas, mesmo que muito pequenas, também foram medidas com o equipamento produzido, fazendo ajuste do suporte com os eletrodos de cobre. No cálculo, as mesmas foram descontadas, para que houvesse a obtenção apenas da resistência da amostra de concreto. Dessa forma, para obtenção da resistividade elétrica, considerando-se a Lei de $\mathrm{Ohm}$, foi seguida a seguinte sequência de cálculo:

Primeiramente, calcula-se a resistência obtida, conforme equação 1:

$$
R_{e}=R_{e+s p}-R_{s p}
$$

Onde: $R_{\mathrm{e}}$ é a resistência elétrica do concreto $(\Omega) ; \mathrm{R}_{\mathrm{e}+\mathrm{sp}}$ é a resistência elétrica do concreto em conjunto com a esponja $(\Omega)$; $\mathrm{R}_{\mathrm{sp}}$ é a resistência elétrica da esponja $(\Omega)$.

Posteriormente, calcula-se a constante de célula "k" pela equação 2 :

$$
k=\frac{S}{L}
$$

Onde: $\mathrm{S}$ é a área da seção transversal perpendicular à corrente $\left(\mathrm{m}^{2}\right)$; L é a altura do corpo de prova $(\mathrm{m})$.

E por fim, a resistividade elétrica é obtida pelo método direto através da equação 3:

$$
\rho_{e}=k \cdot R
$$

Onde: $\rho_{\mathrm{e}}$ é a resistividade elétrica do concreto $(\Omega . \mathrm{m})$; k é a constante de célula obtida $(\mathrm{m})$; e, $\mathrm{R}_{\mathrm{e}}$ é a resistência elétrica calculada $(\Omega)$.

É importante ressaltar que anterior ao início dos ensaios foi feita uma calibração do equipamento confeccionado. Para calibração do método direto, utilizou-se o método superficial ou método dos quatro pontos, como também é chamado. $\mathrm{O}$ equipamento utilizado foi a sonda Wenner com espaçamento entre eletrodos de $50 \mathrm{~mm}$. Os resultados de resistividade elétrica superficial foram obtidos por este equipamento no momento das leituras.

\subsubsection{Teor de umidade}

A resistividade elétrica também foi investigada quanto ao teor de umidade dos concretos. $\mathrm{O}$ ensaio foi realizado na idade de 28 dias em 3 corpos de prova cilíndricos $(100$ x $200 \mathrm{~mm}$ ) para cada mistura. Para confecção da curva do teor de umidade $\mathrm{x}$ resistividade elétrica, as medições de resistividade elétrica e massa dos corpos de prova foram realizadas da condição seco em estufa até saturado, como indicado na norma UNE 83988-1 (AENOR, 2008), onde as leituras dos corpos de prova deverão ser feitas com os mesmos em condição saturado superfície seca.

Seguiu-se o seguinte procedimento: i) Primeiramente, os concretos foram curados em água até a idade estabelecida de ensaio; ii) Em seguida, os concretos foram colocados em estufa à temperatura de $100{ }^{\circ} \mathrm{C}$ por 24 horas; iii) Foram então retirados para resfriamento durante aproximadamente 3 horas, em ambiente de laboratório com temperatura $23^{\circ} \mathrm{C}$; iv) Após esse tempo as amostras foram imersas em água para monitoramento da umidade.

As medidas, de massa e resistividade, foram registradas em intervalos de 60 minutos durante as primeiras 6 horas em imersão em água, e continuaram-se as medições ao completar 24 horas, 48 horas e 72 horas de saturação. Após o resfriamento (passo iii), foi feita a tentativa de medição da resistividade elétrica mas não foi possível, devido à baixa umidade das amostras. 


\section{RESULTADOS E DISCUSSÕES}

Nesta seção os resultados obtidos através dos ensaios que foram realizados serão apresentados.

\subsection{Propriedades mecânicas e físicas}

Para análise mecânica dos concretos foram realizados ensaios de resistência à compressão axial e módulo de elasticidade. Para análise física dos concretos, os ensaios de absorção de água por capilaridade e imersão. Todos eles realizados aos 28 dias de idade. Os resultados médios de 3 corpos de prova cilíndricos em cada ensaio são apresentados na Tabela 2.

Tabela 2 - Resultados médios das propriedades físicas e mecânicas dos concretos estudados

\begin{tabular}{c|c|c|c|c|c|c|c|c}
\hline \multirow{2}{*}{ Mistura } & \multicolumn{2}{|c|}{$\mathbf{f c} 28$ (MPa) } & \multicolumn{2}{c|}{$\begin{array}{c}\text { Módulo de } \\
\text { elasticidade (GPa) }\end{array}$} & \multicolumn{2}{c|}{$\begin{array}{c}\text { Absorção por } \\
\text { capilaridadd (g./2m) }\end{array}$} & \multicolumn{2}{c}{$\begin{array}{c}\text { Absorção por imersão } \\
\text { (\%) }\end{array}$} \\
\cline { 2 - 9 } & Média & C.V.(\%) & Média & C.V. (\%) & Média & C.V. (\%) & Média & C.V. (\%) \\
\hline BRITA_46\% & 24,7 & 0,3 & 26,9 & 6,1 & 0,51 & 9,3 & 6,17 & 2,9 \\
\hline BRITA_43\% & 26,7 & 1,0 & 26,2 & 8,8 & 0,37 & 3,2 & 5,71 & 2,1 \\
\hline BRITA_40\% & 23,9 & 3,5 & 23,4 & 5,0 & 0,40 & 3,7 & 5,81 & 0,5 \\
\hline
\end{tabular}

Com os resultados apresentados na tabela acima, verifica-se que a mistura BRITA_43\% apresentou o melhor resultado de resistência à compressão axial. Com relação a mistura BRITA_43\%, concretos das misturas BRITA_40\% apresentaram uma redução de $11 \%$. E para BRITA_46\%, houve uma redução de 8\%. Os concretos com 40\% e 46\% de volume final de brita não apresentaram praticamente nenhuma diferença na resistência à compressão axial, apenas de $3 \%$.

Quanto ao módulo de elasticidade, verifica-se uma tendência de aumento com o aumento no teor de agregado utilizado, apesar de resultados bastante semelhantes para às misturas BRITA_46\% e BRITA 43\%. A mistura BRITA_46\% apresentou um aumento de $15 \%$ em relação ao concreto BRITA_40\%. Nesse caso, o comportamento observado mostra que o teor de agregado influenciou diretamente na evolução do módulo de elasticidade, isto está atrelado a condição que o módulo de elasticidade dos agregados é maior que o da pasta de cimento (MEHTA; MONTEIRO, 2008).

A mistura BRITA_46\% apresentou a maior absorção de água por capilaridade e por imersão, o que pode estar atrelado a porosidade do material devido a uma quantidade maior de zonas de transição com o aumento no teor de agregado graúdo da mistura. Por outro lado, os concretos com BRITA_40\% e BRITA_43\% apresentaram resultados bastante semelhantes.

O gráfico que apresenta as configurações das curvas de absorção de água por capilaridade por área transversal $\left(\mathrm{g} / \mathrm{cm}^{2}\right)$ em função do tempo $\left(\mathrm{h}^{1 / 2}\right)$ das três misturas estudadas é apresentado na Figura 2.

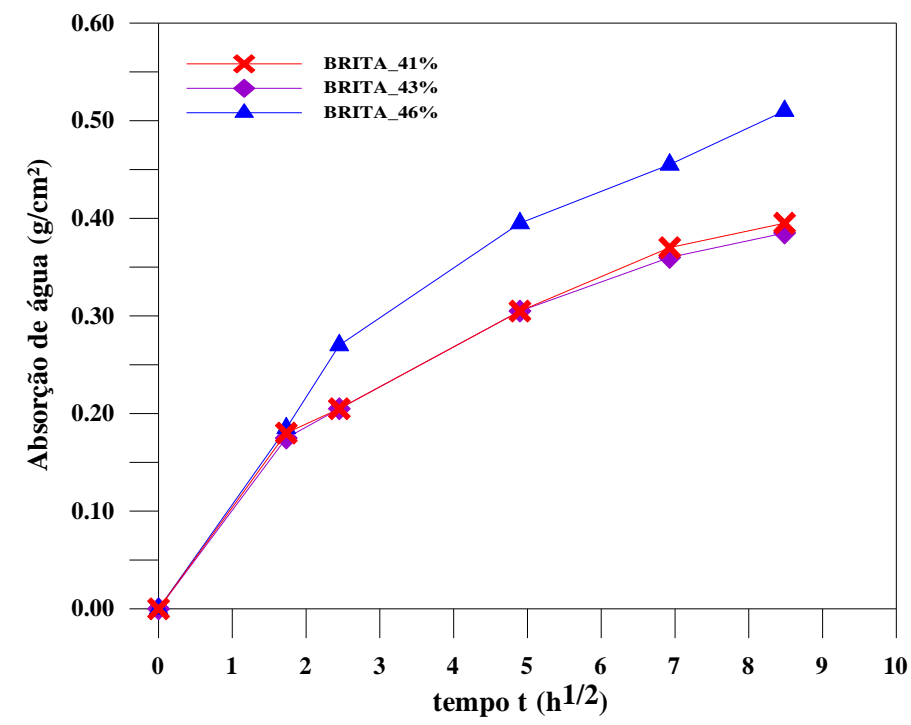


Figura 2: Absorção de água por capilaridade das misturas

Foi percebido que além da resistência mecânica, as porosidades capilares não tiveram uma influência regular com a mudança no teor de agregado graúdo. De certa forma, os concretos produzidos não atingiram altos valores de absorção de água por capilaridade, ou seja, as pastas de cimento tiveram uma qualidade semelhante em todas misturas. Conforme os estudos de Hou et al. (2017) não existe correlação significativa entre porosidade e teor de agregado.

\subsection{Resistividade elétrica pelo método direto}

\subsubsection{Calibração do método}

Para validação do método de ensaio utilizado por este estudo, primeiramente foi feita a calibração do equipamento produzido. Dessa forma, utilizando-se do método superficial, atráves da sonda Wenner foram realizadas três leituras de resistência para cada corpo de prova, em eixos espaçados a $120^{\circ}$ entre si. A partir das leituras foram obtidos os valores de resistividade elétrica superficial e feitas as médias para cada corpo de prova.

Com o mesmo corpo de prova, foram realizadas as leituras no equipamento confeccionado pelo método direto, e a partir deste momento foi possível estabelecer uma correlação entre os dois métodos para validação do estudo. Para obtenção dos resultados de resistividade pelo método direto, o valor da resistência elétrica das esponjas úmidas foi de $8,17 \Omega$ e foi medida no início do ensaio com o equipamento produzido. E então, para as amostras utilizadas no ensaio direto, a constante de célula " $k$ " variou entre 0,0395 a 0,0402 m a depender da largura $(\mathrm{m})$ e área $\left(\mathrm{m}^{2}\right)$ de cada corpo de prova utilizado.

A Figura 3 mostra a correlação encontrada entre os dois métodos.

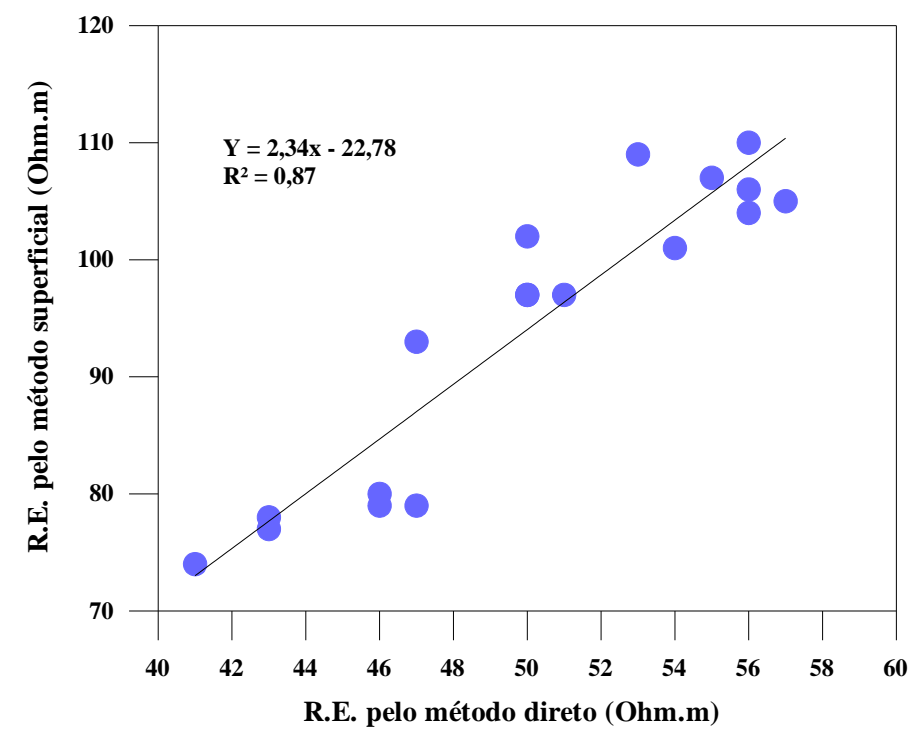

Figura 3: Relação entre método direto e método superficial

A relação linear exibida na Figura 3 se aproxima dos resultados experimentais encontrados por Gudimettla e Crawford (2014), Azarsa e Gupta (2017), entre outros autores. O coeficiente de determinação ( $\left.\mathrm{R}^{2}\right)$ se aproxima do obtido por Ghosh e Tran (2015).

Os valores obtidos pela resistividade superficial neste estudo foram 1,88 vezes maiores que os resultados provenientes do método direto do equipamento produzido. Em um estudo mais amplo Gudimettla e Crawford (2014) havia encontrado uma média de valores que foram 1,9 vezes mais altos, o que indica uma grande proximidade ao encontrado por este estudo.

Dessa forma, com o equipamento calibrado, os ensaios de resistividade elétrica pelo método direto foram iniciados. 


\subsubsection{Efeito do teor de agregado na resistividade elétrica pelo método direto}

Os resultados médios de resistividade elétrica obtidos experimentalmente pelo método direto aos 28 e 56 dias de idade para os diferentes teores de agregado graúdo são exibidos na Tabela 3.

Tabela 3 - Resistividade elétrica pelo método direto dos concretos

\begin{tabular}{|c|c|c|c|c|}
\hline \multirow{2}{*}{ Mistura } & \multicolumn{2}{|c|}{ 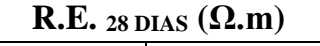 } & \multicolumn{2}{|c|}{ 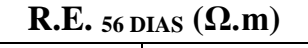 } \\
\hline & Média & C.V. $(\%)$ & Média & C.V. $(\%)$ \\
\hline BRITA_46\% & 51 & 5,9 & 55 & 3,1 \\
\hline BRITA_43\% & 46 & 3,0 & 50 & 2,5 \\
\hline BRITA_40\% & 43 & 2,7 & 49 & 2,3 \\
\hline
\end{tabular}

Os resultados apresentados na Tabela 3 sugerem que a resistividade elétrica aumenta com a inclusão de agregado graúdo na mistura, tanto aos 28 , quanto aos 56 dias. A utilização de $40 \%$ de agregado graúdo gerou uma redução de $7 \%$ com relação aos concretos da mistura BRITA_43\%. Já quanto à utilização de $46 \%$ de agregado gerou um aumento de $11 \%$. Em relação aos concretos BRITA_40\% e BRITA_46\%, houve um acréscimo de 19\% na resistividade elétrica dos concretos com o maior volume de brita, aos 28 dias. Este comportamento se deve ao volume de agregado graúdo, ou seja, a medida que há um aumento no teor, ocorre uma ascendência na resistividade elétrica obtida.

Sengul (2014), Hou et al. (2017) e Princigallo et al. (2003) também relataram que há variação na resistividade com o aumento no teor de agregado graúdo, e esses resultados condizem com o observado por estes autores. O aumento da resistividade elétrica observado com o aumento do teor de agregado demonstra que a condutividade elétrica é transportada mais facilmente pela rede de poros da pasta, do que pelos agregados.

Hou et al. (2017) observaram que os agregados atuam como obstáculos elétricos que impedem uma transmissão maior de corrente, ou seja, a inclusão cada vez maior de teor de agregado graúdo à pasta de cimento não altera a hidratação cimentícia, mas servem como verdadeiros "bloqueadores" de corrente elétrica. E então, ao contrário, os agregados submersos aleatoriamente na pasta (e em menor quantidade) poderão ocasionar uma diminuição da resistividade elétrica do concreto, pois a condução elétrica ocorrerá essencialmente pela pasta de cimento.

Whintington et al. (1981) ressaltam que as resistividades elétricas dos agregados são de várias ordens maiores que as dos concretos. Com isso, a corrente elétrica geralmente utiliza-se da pasta de cimento para condução, ou seja, o caminho de menor resistência. Os autores informam em seu estudo que enquanto a resistividade do concreto úmido está em torno de 25-45 $\Omega . \mathrm{m}$, a pasta de cimento varia entre 10-13 $\Omega . \mathrm{m}$.

O método direto, utilizado neste estudo, possibilitou que a corrente fosse transportada por todo interior do corpo de prova, e pode também justificar este comportamento. Como a corrente ultrapassa por todo interior da microestrutura, quanto mais "livre" ou porosa a pasta de cimento estiver, mais facilidade a corrente obterá para transporte pelos fluídos existentes no interior do concreto.

Quanto à análise da resistividade elétrica referente ao tempo de cura do concreto foi visto que após os 56 dias de idade, todos os concretos aumentaram a sua resistividade elétrica. Essa evolução pode ser melhor observada na Figura 4. 


\section{CBPAT 2020 \\ CONGRESSO BRASILEIRO DE PATOLOGIA DAS CONSTRUÇÕES

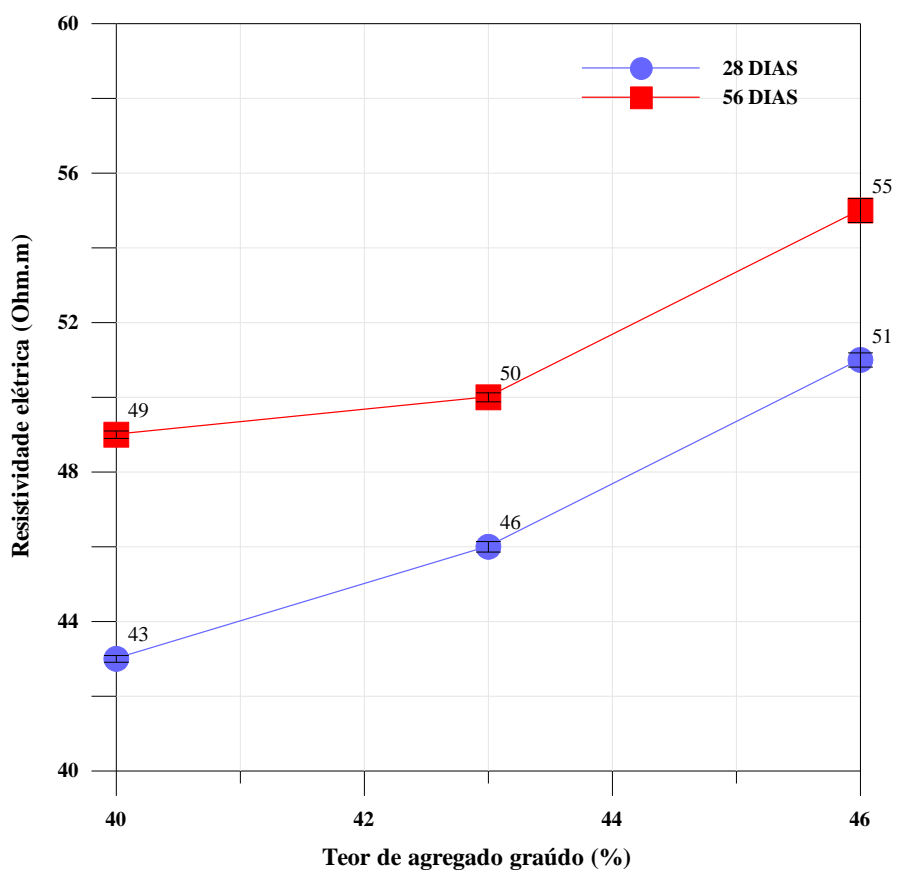

Figura 4: Resistividade elétrica pelo método direto x teor de agregado graúdo

É evidenciado que, com o tempo de hidratação, a resistividade da amostra se torna cada vez maior porque a microestrutura do concreto se torna cada vez mais densa e o tamanho dos poros no seu interior se torna cada vez mais estreito. Como consequência, a resistividade elétrica aumenta. Autores como Princigallo et al. (2003), Godinho et al. (2018); Ghoddousi e Adelzade (2017); e Kurda; Brito e Silvestre (2019) também constataram maior resistividade elétrica do concreto, quanto maior o tempo de hidratação.

Foi também possível inferir diante dos resultados, que após os 28 dias, a diferença da resistividade elétrica entre a mistura BRITA_40\% e as outras duas misturas diminuiu substancialmente com o tempo. O concreto com menor volume de brita possui um maior volume de argamassa, continuando dessa forma com uma maior hidratação do cimento ao longo do tempo. Devido às reações de hidratação da argamassa, as dimensões dos poros podem ter sido reduzidas, a porosidade e a tortuosidade da rede de poros alterada, e como consequência a mobilidade iônica diminuiu ou foi dificultada, o que pode ser considerado como a principal razão para que esta mistura obtivesse o melhor avanço da resistividade elétrica aos 56 dias.

\subsubsection{Efeito do teor de umidade da amostra na resistividade elétrica pelo método direto}

A Figura 5 apresenta a variação da resistividade elétrica em relação ao teor de umidade de cada mistura estudada. Estabeleceu-se, como referência, que a absorção de água após 72 horas corresponderia ao percentual de $100 \%$ de saturação dos concretos. 

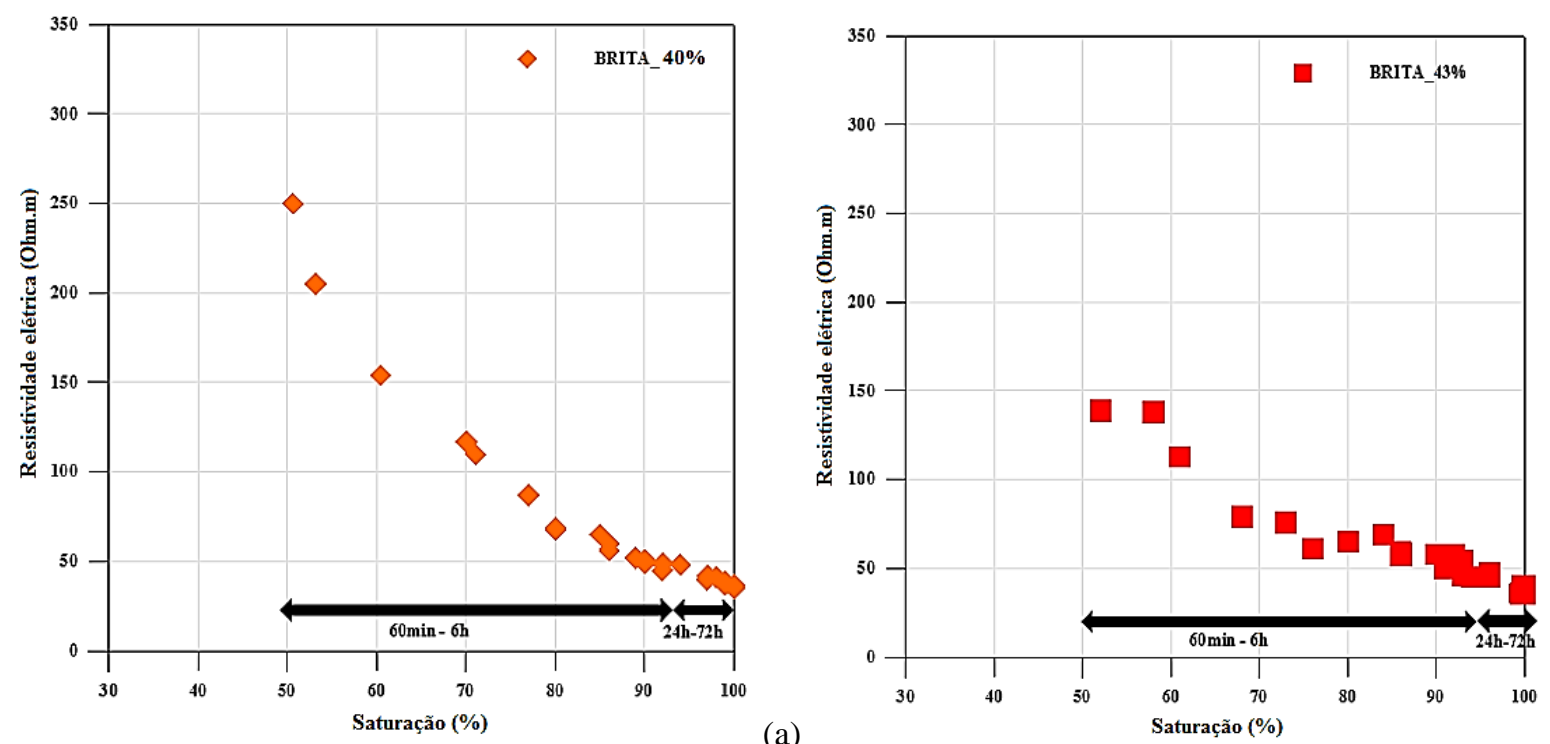

(a)

(b)

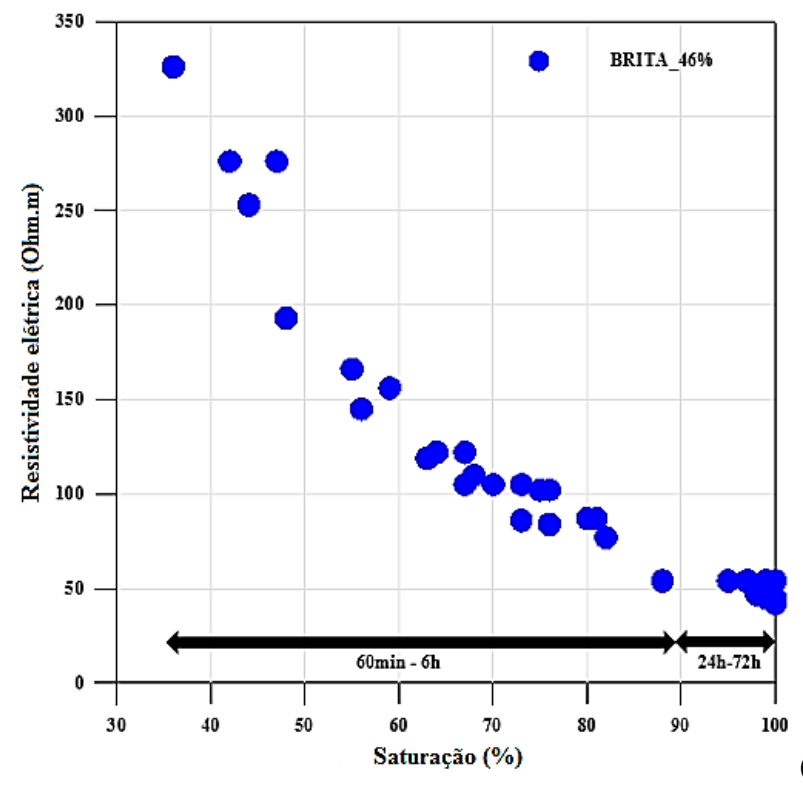

(c)

Figura 5: Resistividade elétrica $x$ teor de umidade. a) mistura BRITA_40\%,b) mistura BRITA_43\%,c) mistura BRITA_46\%

Os resultados exibidos na Figura 5 mostram que a resistividade elétrica do concreto diminui quando o teor de umidade aumenta. De forma geral, as resistividades elétricas apresentadas variaram entre 37 a $326 \Omega$.m, enquanto o grau de saturação esteve entre $36 \%$ a $100 \%$.

Conforme literatura, Sbartai et al. (2007) e Bonnet e Balayssac (2018) indicam um teor de umidade acima de 40\% para avaliação de níveis de saturação, pois abaixo desse nível as medições são dificultadas. Justifica-se que com um teor de umidade mais baixo, a continuidade da solução intersticial desaparece e a corrente elétrica não pode circular. Dessa forma, para que houvesse quantidade suficiente de água na amostra, que possibilitasse a realização do ensaio, as medições foram iniciadas a partir da primeira hora de imersão. Nesse caso, verificou-se que com níveis de saturação acima de 36\%, as medições de resistividade elétrica dos concretos puderam ser realizadas.

O maior aumento no percentual de saturação ocorreu na primeira hora de molhagem, e isto possibilitou a medida de resistividade elétrica, por seguinte, de hora em hora houveram avanços no teor de umidade e consequente redução na resistividade, até ser atingida as 72 horas de imersão. 
O acentuado aumento no teor de umidade dos concretos na primeira hora de saturação dos concretos deve-se ao fato que provavelmente as amostras estavam totalmente secas após as 24 horas em estufa a $100^{\circ} \mathrm{C}$ e como a maior parte da condutividade é do fluido poroso, estes são eletricamente condutores, fato que também foi observado por Charmch (2015) e Elkey e Sellevold (1995) realizado de forma inversa.

Ainda, observando os dados da Figura 5, é verificado que a partir do espaço de tempo entre 24 horas a 72 horas, houve uma faixa mínima de mudança valores de resistividade nas três misturas analisadas. Os concretos seguiram uma tendência onde apresentaram um nível acentuado de teor de umidade nas primeiras 24 horas de saturação, atingindo um percentual maior que $90 \%$ na umidade. Lopez e Gonzalez (1998) observaram característica semelhante em seu estudo, no entanto, os concretos analisados pelos autores seguiram do estado saturado para o estado seco, dessa forma, os valores de resistividade mudaram dentro de uma faixa estreita quando o nível de saturação dos poros variava entre 60 e $100 \%$. Então, entre 60 e 30\%, a resistividade apresentou um limite correspondente a um nível de saturação em que a medição era impossível.

A diminuição da resistividade elétrica com o aumento no grau de saturação da amostra é atribuída à quantidade de água contida nos poros dos concretos que melhoram o fluxo da corrente elétrica. Whiting e Nagi (2003) relatam que a resistividade elétrica do concreto é função da mobilidade e concentração dos íons na solução aquosa dos poros.

Quanto às caracteristicas de teor de agregado graúdo nestes resultados, o que se pode inferir apenas é que ao atingir o nível de $100 \%$ de umidade, os concretos da mistura BRITA_46\% ainda assim alcançaram um valor de resistividade elétrica superior aos demais, confirmando a tendência já exibida na Figura 4. No entanto, atingiram valores inferiores ao apresentados na Tabela 3, o que pode estar atrelado a um efeito da temperatura de ensaio. A temperatura também pode ter influenciado na resistividade elétrica medida, principalmente pelo resultado do aumento da mobilidade iônica da solução de poros do concreto. Alterações no volume do fluido poroso podem ter causado efeito nos resultados de resistividade elétrica devido ao aquecimento e molhagem (resfriamento). Conforme Medeiros-Junior (2014), ao secar o concreto a uma temperatura de $100^{\circ} \mathrm{C}$, pode ocorrer uma ebulição da água interna nos corpos de prova, o que vem modificar a microestrutura das amostras, pela ocasião de fissuras internas.

\section{CONCLUSÕES}

Com base nos resultados do estudo podem ser retiradas as seguintes conclusões quanto ao efeito do teor de agregado e da umidade da amostra sobre a resistividade elétrica do concreto.

O agregado graúdo não muda a microestrutura do concreto, mas serve como uma barreira elétrica, podendo assim ocasionar aumento na resistividade. A visibilidade desse comportamento foi melhor evidenciada nos concretos BRITA_40\% e BRITA_46\%, com uma diferença de $6 \%$ no volume de agregado, houve um aumento de $19 \%$ na resistividade elétrica. Indicando que a resistividade é sensível a inclusão de agregados graúdos e sugerindo que uma maior proporção elevaria cada vez mais a sua resistividade.

Em relação ao teor de umidade dos concretos, é evidenciado que a resistividade elétrica do concreto diminui quando o percentual de saturação aumenta. No entanto, não houve nenhuma relação significativa entre a mudança no teor de agregado, apenas constatado que a resistividade obtida após a saturação continuou sendo maior para a mistura BRITA_46\%.

Por fim, é identificada a necessidade de novas pesquisas com a utilização do método aqui exposto.

\section{AGRADECIMENTOS}

À Fabesp e à Capes pelo apoio financeiro, e ao LEDMA/UFBA pela realização do ensaio de resistividade pelo método dos 4 pontos

\section{REFERÊNCIAS}

ANDRADE, C. Calculation of initiation and propagation periods of service life of reinforcements by using the electrical resistivity. International Symposium: Advances in Concrete through Science and Engineering, v. (1), p. 1-8, 2004. 
ASOCIACIÓN ESPAÑOLA DE NORMALIZACIÓN Y CERTIFICACIÓN (AENOR). UNE-83988-1: Durabilidad del hormigón. Métodos de ensayo. Determinación de la resistividad eléctrica. Parte 1: Método directo (método de referencia). Madrid, 2008.

ASSOCIAÇÃO BRASILEIRA DE NORMAS TÉCNICAS. NBR 5739: Concreto - Ensaio de compressão de corpos de prova cilíndricos. Rio de Janeiro, 2018.

ASSOCIAÇÃO BRASILEIRA DE NORMAS TÉCNICAS (ABNT). NBR 7211: Agregados para concreto Especificação. Rio de Janeiro, 2019.

ASSOCIAÇÃO BRASILEIRA DE NORMAS TÉCNICAS (ABNT). NBR 8522: Concreto - Determinação dos módulos estáticos de elasticidade e de deformação à compressão. Rio de Janeiro, 2017.

ASSOCIAÇÃO BRASILEIRA DE NORMAS TÉCNICAS (ABNT). NBR 9778: Argamassa e concreto endurecidos Determinação da absorção de água, índice de vazios e massa específica. Rio de Janeiro, 2009.

ASSOCIAÇÃO BRASILEIRA DE NORMAS TÉCNICAS (ABNT). NBR 9779: Argamassa e concreto endurecidos Determinação da absorção de água por capilaridade. Rio de Janeiro, 2012.

ASSOCIAÇÃO BRASILEIRA DE NORMAS TÉCNICAS (ABNT). NBR 11578: Cimento Portland composto Especificação. Rio de Janeiro, 1997.

ASSOCIAÇÃO BRASILEIRA DE NORMAS TÉCNICAS. NBR NM 5738: Concreto - Procedimento para moldagem e cura de corpos-de-prova. Rio de Janeiro, 2015.

AZARSA, P.; GUPTA, R. Electrical Resistivity of Concrete for Durability Evaluation: A Review. Advances in Materials Science and Engineering, p. 0-30, 2017.

BONNET, S.; BALAYSSAC, J.P. Combination of Wenner resistivimeter and Torrent permeameter methods for assessing carbonation depth and saturation level of concrete. Construction and Building Materials, v. 188, p. 1149$1165,2018$.

CHARMCHI, G. The Role of Concrete Maturity in Resistivity-Based Performance Specifications. Thesis. University of Toronto. 2015.

ELKEY, W.; SELLEVOLD, E. Electrical resistivity of concrete. Norwegian Road Research Laboratory. Oslo, 1995.

HELENE, P. R. L. Contribuição ao estudo da corrosão em armaduras de concreto armado. Tese. Escola Politécnica, Universidade de São Paulo, São Paulo, 1993. 231 p.

HOU, T. C.; NGUYEN, V. K.; SU, Y. M.; CHEN, Y. R.; CHEN, P. J. Effects of coarse aggregates on the electrical resistivity of Portland cement concrete. Construction and Building Materials, v. 133, p. 397-408, 2017.

GHODDOUSI, P.; ADELZADE S. L. Study on hydration products by electrical resistivity for self-compacting concrete with silica fume and metakaolin. Construction and Building Materials, v. 154, p. 219-228, 2017.

GHOSH, P.; TRAN, Q. Composites Influence of parameters on surface resistivity of concrete. Cement and Concrete Composites, v. 62, p. 134-145, 2015.

GODINHO, J. P.; OLIVEIRA, R. L. N. de; CAPRARO, A. P. B.; RÉUS, G. C.; MEDEIROS, M. H. F. de. Influência do formato dos corpos de prova e da idade de curas nas leituras de velocidade de ultrassom, resistividade elétrica e resistência a compressão axial. $3^{\circ}$ Simpósio Paranaense de Patologia das Construções ( ${ }^{\circ}$ SPPC), artigo n. 3SPPC1011, p. 116-129, 2018.

GUDIMETTLA, J. M.; CRAWFORD, G. L. (2014). Field experience in using Resistivity Tests for Concrete. 94th Annual Meeting of the Transportation. Washington, 2014. 
JESUS, L. S. A resistividade elétrica do concreto e a sua correlação com a durabilidade das estruturas. Engenharia Estudo e Pesquisa. ABPE, v. 1, p. 26-33. 2018.

KURDA, R. BRITO, J.; SILVESTRE, J. Combined influence of recycled concrete aggregates and high contents of fly ash on concrete properties, Construction and Building Materials, v. 157, p. 554-572, 2017.

LAYSSI, H.; GHODS, P.; ALIZADEH, A.R.; SALEHI, M. The electrical resistivity of concrete. ACI Material Journal. p. 41-46, 2015.

LOPEZ, W.; GONZALEZ, J.A. Influence of the degree of pore saturation on the resistivity of concrete and the corrosion rate of steel reinforcement. Cement and Concrete Research, v. 23, p. 368-376, 1993.

MEDEIROS-JUNIOR, R.A. Estudo da resistividade do concreto para proposta de modelagem de vida útil Corrosão das armaduras devido à penetração de cloretos. 2014. 234 p. Tese (Doutorado). Programa de PósGraduação em Engenharia de Infraestrutura Aeronáutica, São José dos Campos, 2014.

MEHTA, P. K.; MONTEIRO, P. J. M. Concreto: Estruturas, Propriedades e Materiais. São Paulo: PINI, 2008.

MENDES, S. E. S.; OLIVEIRA, R. L. N.; CREMONEZ, C.; PEREIRA, E.; PEREIRA, E.; MEDEIROS-JUNIOR, R. A. Electrical resistivity as a durability parameter for concrete design: Experimental data versus estimation by mathematical model. Construction and Building Materials, v. 192, p. 610-620, 2018.

PRINCIGALLO, A.; BREUGEL, K. V.; LEVITA, G. Influence of the aggregate on the electrical conductivity of Portland cement concretes. Cemente and Concrete Research, v. 33, p. 1755 -1763, 2003.

SANTOS, L. Avaliação da resistividade elétrica do concreto como parâmetro para a previsão da iniciação da corrosão induzida por cloretos em estruturas de concreto. 2006. 178 f. Dissertação (Mestrado em Estruturas e Construção Civil). Universidade de Brasília - UNB, Brasília, 2006.

SILVA, P.; DE BRITO, J. Electrical resistivity and capillarity of self-compacting concrete with incorporation of fly ash and limestone filler. Advances in Concrete Construction, v. 1(1), p. 65-84, 2013.

SBARTAÏ, Z. M.; LAURENS, S.; RHAZI, J.; BALAYSSAC, J. P.; ARLIGUIE, G. Using radar direct wave for concrete condition assessment: Correlation with electrical resistivity. Journal of Applied Geophysics, v. 62(4), p. 361374. 2007.

SENGUL, O. Use of electrical resistivity as an indicator for durability. Construction and Building Materials, v. 73, p. 434-441, 2014.

TOMLINSON, D.; MORADI, F.; HAJILOO, H.; GHODS, P.; ALIZADEH, A.; GREEN, M. Early age electrical resistivity behaviour of various concrete mixtures subject to low temperature cycling. Cement and Concrete Composites, v. 83, p. 323-334, 2017.

WHITING, D. A.; NAGI, M. A. Electrical Resistivity of Concrete- A Literature Review. PCA R\&D Serial No. 2457. Portland Cement Association, Illinois, 2003.

WHITTINGTON, H. W.; MCCARTER, J.; FORDE, M. C. The conduction of electricity through concrete. Department of Civil Engineering and Building Science. University of Edinburgh. 1981. 